\title{
A CONSTRUÇÃO DA CONFIABILIDADE NA RELAÇÃO MÃE-BEBÊ A PARTIR DO CONCEITO DE ILUSÃO: UMA PERSPECTIVA WINNICOTTIANA
}

\section{THE CONSTRUCTION OF RELIABILITY IN THE MOTHER-BABY RELATIONSHIP FROM THE CONCEPT OF ILLUSION: A WINNICOTTIAN PERSPECTIVE}

\section{Ana Lúcia Braz Rios Pereira ${ }^{1}$}

\begin{abstract}
Resumo: Este trabalho apresenta a interpretação do conceito de ilusão, vinculando-o à teoria do amadurecimento e na relação de confiabilidade entre mãe e bebê presente na perspectiva psicanalítica de D.W. Winnicott. No primeiro momento, retoma as afirmações freudianas sobre a envergadura da noção de ilusão para a psicanálise em paridade com a terminologia pulsional (pulsão de vida e de morte) e os objetivos civilizacionais. Posteriormente, apresenta a teoria do amadurecimento de Winnicott, a partir dos seus conceitos basilares, tangendo a maternidade e o desenvolvimento do indivíduo. Por fim, relaciona as afirmações anteriores com a construção da confiabilidade na relação mãe-bebê a partir da experiência de ilusão propiciada pelo espaço transicional.
\end{abstract}

Palavras-chave: Confiabilidade; ilusão; maternagem; amadurecimento.

Abstract: This work presents the interpretation of the concept of illusion, linking it to the theory of maturity and the relationship of trust between mother and baby present in the Winnicott psychoanalytic perspective. In the first instance, it takes up the Freudian statements about the scope of the notion of illusion for psychoanalysis in parity with the instinctual terminology (life and death instinct) and civilizational goals. Later, it presents the Winnicott's theory of maturity from its basic concepts in link with the maternity and the development of the subject. Finally, it relates previous statements to the construction of reliability in the mother-baby relationship from the experience of illusion provided by the transitional space.

Keywords: Reliability; illusion; maternity; maturation.

\section{INTRODUÇÃO}

Desde o seu advento, a psicanálise sempre apresentou a sua peculiaridade dentre os demais saberes que investigam e trabalham com o psiquismo humano, a saber: a constituição do sujeito é resultado de experiências vividas em suas fases iniciais, ou seja, na infância, especialmente na relação com o outro. Sigmund Freud, pai da psicanálise, revolucionou as concepções antropológicas ao realizar o golpe da terceira ferida narcísica por parte das pesquisas científicas, aquele que atribuiu uma "importância psíquica da sexualidade e a inconsciência da vida sexual" (FREUD, 1996a, p. 153). Assim diz Freud:

Só os fatos da infância explicam a sensibilidade aos traumatismos futuros e só com o descobrimento desses restos de lembranças, quase regularmente olvidados, e com a volta deles à consciência, é que adquirimos poder de afastar os sintomas. (FREUD, 1996b, p. 54).

Nesse trecho, vê-se elucidada a teoria de que já existe atividade sexual desde os primórdios da vida humana. Anteriormente, em sua obra Três ensaios sobre a teoria da sexualidade (1905), Freud já havia desvelado a libido e sua incidência nas zonas erógenas enquanto atividade sexual primitiva. Logo, desde o início, o ser humano é

\footnotetext{
${ }^{1}$ Mestrado em Bioengenharia pela Universidade do Vale do Paraíba, Brasil. E-mail: anabraz.rp@hotmail.com.
} 
inserido no fundamento da ética humana: o desejo.

A psicanálise, na medida em que se propôs como uma teoria da subjetividade, busca a determinação dos atos, motivações e desejos do homem, a partir da formação do inconsciente: originado das experiências sexuais infantis que sofreram recalque, mas que continuam a exercer seu poder enquanto sobre determinação inconsciente. Segundo ele, tudo o que se passou é preservado lado a lado com versões transformadas, surgidas por meio do inconsciente, e de que estes elementos podem ser trazidos de novo à luz.

Assim, buscando uma explicação metapsicológica para os sintomas, Freud empreende um esforço para analisar o limite entre o somático (biológico) e o psíquico.

Assim, o limite entre o somático e o psíquico se encontra no conceito de pulsão característica sine qua non do aparelho psíquico caracterizada como "a região mais obscura e inacessível da mente" (FREUD, 1996c, p. 17). O pai da psicanálise afirma que "a essência mais profunda da natureza humana consiste em impulsos instintuais de natureza elementar, semelhantes em todos os homens e que visam à satisfação de certas necessidades primevas" (FREUD, 2006d, p. 290). Então, pela energia sexual (a libido), o ser humano possuiria um 'estado natural' marcado pela agressividade; Tal como, de maneira pessimista, escreveu afirmando:

\footnotetext{
o ser humano não é um ser manso, amável, capaz no máximo de defender-se quando o atacam, mas é lícito atribuir a sua dotação instintiva uma boa quota de agressividade. Em consequência, 0 próximo não é somente um possível auxiliar e objeto sexual, mas sim uma tentação para satisfazer nele a agressão, explorar sua força de trabalho sem ressarci-lo, usá-lo sexualmente sem seu consentimento, despossuí-lo de seu patrimônio, humilhá-lo, infligir-lhe dor, martirizá-lo e assassiná-lo (FREUD, 2006e, p. 115).
}

Com uma perspectiva em que se tem um grau de sofisticação maior devido à revolução dada pela sua teoria da sexualidade, Freud afirma que o sentimento de desamparo é análogo ao afeto de insegurança decorrente do medo, uma vez que, ainda na obra $O$ mal-estar na civilização, o pai da psicanálise insiste que uma das ameaças do sofrimento vem justamente do mundo externo "que pode voltar-se contra nós com forças de destruição esmagadoras e impiedosas". (FREUD, 1996e, p. 84). Nesse sentido, em 1914, em seu texto Sobre o narcisismo: uma introdução, surge o conceito do desejo, no sentido de sua satisfação, como uma tentativa do psiquismo em recuperar o narcisismo perdido da infância, quando o eu era seu próprio ideal (narcisismo primário).

Desse modo, como apontam Laplanche e Pontalis: "Esse estado do narcisismo designa o primeiro grau do mesmo: quando a criança toma a si mesma como objeto de amor, antes de escolher objetos exteriores. Tal estado corresponderia à crença da criança na onipotência dos seus pensamentos." (LAPLANCHE; PONTALIS, 2001, p. 
290). Não obstante, também se define como uma defesa contra o reconhecimento de desamparo e da dependência que ameaçam a ilusão da completude narcísica.

Em 1920, na obra Além do princípio de prazer, Freud coloca essa reflexão introduzindo-a em seu argumento segundo o qual o psiquismo resulta numa tensão dialética entre o recalque e as pulsões. (FREUD, 1996c, p. 50). Assim, o pai da psicanálise apresenta o conceito de ilusão benévola que seria, em suma, o desejo humano de crer numa pulsão que protegeria do reconhecimento da finitude da existência e da existência da pulsão de morte. Assim diz Freud:

Nesse sentido, a ilusão funciona como uma negação da ordem pulsional, ou seja, negação da compulsão à repetição e da pulsão de morte. Esse sentido universal seria o que Freud, nesse trabalho, insiste como sendo o retorno a um 'estado anterior de coisas'. (FREUD (1920), 1996c, p. 54-55).

Destarte, em 1927, Freud aprofunda a temática segundo a qual o conceito de ilusão protagonizado por ele até o momento é o solo do qual se originam as formações culturais ou os artefatos psíquicos da civilização, principalmente os ideais, a arte e, principalmente, a religião. Para Freud, a religiosidade seria um dos artifícios criados pela civilização como uma forma de compensar os sofrimentos e privações que a vida civilizada impõe. (Cf. FREUD, 1996e, p. 26) Assim, se os homens buscassem simplesmente a realização de seus desejos acabariam destruindo uns aos outros.

Os indivíduos fazem então um pacto de defesa mútua contra as ameaças da natureza. Surge assim a cultura como tarefa para o homem se autoconservar diante do poder supremo da natureza (Cf. MATOS, 2006, p. 139). De modo que, assim, "Trabalha-se então com todos para o bem de todos" (FREUD, 1996e, p. 85).

Desse modo, nesse contexto em que o pai da psicanálise apresenta a religião como um fator inevitável e derivada do desejo humano de proteção e de carência (paterna), enquanto marca indelével de uma experiência constitutiva de desamparo, ele define o conceito de ilusão:

Quando digo que todas essas coisas são ilusões, devo definir o
significado da palavra. Uma ilusão não é a mesma coisa que um erro,
nem tampouco um erro. (...) O que é característico das ilusões é o
fato de derivarem de desejos humanos. (...) As ilusões não precisam
ser necessariamente falsas, ou seja, irrealizáveis, ou em contradição
com a realidade (...) Podemos, portanto, chamar uma crença de
ilusão quando uma realização de desejo constitui fator proeminente
em sua motivação e, assim, procedendo, desprezamos suas relações
com a realidade, tal como a própria ilusão não dá valor à verificação
(FREUD (1930), 1996, p. 43).

Assim, a religião e os ideais da cultura se concatenam ao universo ilusório, a partir do momento em que são manifestações de tentativa de conservar um "estado de coisas" relativas ao narcisismo, as quais compensam os limites impostos pelo princípio de realidade. (FREUD (1920), 1996c, p. 55) Tal princípio impõe-se sobre o primeiro, 
assumindo-se como regulador, de modo que "a procura por satisfação já não se efetua pelos caminhos mais curtos, mas faz desvios e adia o resultado em função das condições impostas pelo mundo exterior" (LAPLANCHE; PONTALIS, 2001, p. 368).

É nessa linha de pensamento que surge a reflexão de Donald W. Winnicott ${ }^{2}$ que, posterior à Anna Freud e Melaine Klein, dá continuidade à abordagem de seus predecessores ingleses e focaliza a questão do desenvolvimento infantil a partir das circunstancialidades da criança. Embora Winnicott tenha mantido sua filiação com Freud, eles diferem quanto ao conceito de ilusão. Entretanto, antes da apresentação deste conceito criado pelo psicanalista inglês, apresentar-se-á brevemente os pilares fundamentais de sua teoria do amadurecimento.

Segundo ele, "precisamos chegar a uma teoria do amadurecimento normal para podermos ser capazes de compreender as doenças e as várias imaturidades, uma vez que não nos damos por satisfeitos a menos que possamos preveni-las e curá-las" (WINNICOTT, 1983, p. 65). Ademais, o psicanalista inglês discorda do pai da psicanálise, no sentido da explicação a partir do conceito de agressividade, ou seja, de que existia uma pulsão agressiva natural do ser humano, nem tampouco a noção da libido em se tratando da relação do bebê com a sua mãe. Para ele, se a sociedade se encontra em perigo "não é por causa da agressividade dos homens, em consequência da repressão da agressividade pessoal nos indivíduos" (WINNICOTT, 1978. p. 288).

Assim, para além da questão edípica e das fases do desenvolvimento da libido, o psicanalista inglês propõe outro viés (sem romper com o essencial de Freud) priorizando as necessidades do ego e entendendo o desenvolvimento infantil a partir do desenvolvimento do ego (e não do id); tal como bem elucida Jacques André:

Para além da provocação lapidar, Winnicott ressalta uma evidência: a conservação da vida, nos primeiros tempos, é tudo, menos uma autoconservação. Para nascer, viver, sobreviver, incluindo psiquicamente, é preciso que haja ao menos duas pessoas. A psicanálise contentou-se durante muito tempo em reduzir à fome e à sede as primeiras necessidades. Mas elas estão longe de ser as únicas: calor, segurança, carinho... As trocas sensoriais (sorrisos, choros, vocalismos) do recém-nascido com a figura do apego, geralmente a mãe, são múltiplas e interativas (ANDRÉ, 2015, p. 17).

Nesse sentido, torna-se nítido o fato de que o pensamento winnicottiano se dá na via do cuidado e da preocupação materna primária; de modo que, no processo analítico, é esse o papel que o analista deve se inspirar e ocupar o lugar: o de um protagonista engajado com o cuidado do indivíduo. Sobre isso, Winnicott afirma que aqueles bebês que, no início, não recebem cuidados suficientemente bons, "não

\footnotetext{
2 Donald Woods Winnicott nasceu em 1896, na Inglaterra e morreu em 1971, portanto, aos 75 anos. Formou-se médico e optou pela pediatria. Na Grã-Bretanha, ele foi o pioneiro da psicanálise de crianças, tendo alcançado renome internacional devido à consistência de suas contribuições para o entendimento da criança e do seu desenvolvimento. Seu foco de interesse estava voltado para as relações afetivas desta no seio da família, notadamente com a mãe. (...) Winnicott interessou-se pelo trabalho com crianças ao dar assistência às vítimas da Segunda Guerra Mundial que haviam perdido seus pais. Era apaixonado pelo seu trabalho com as crianças. Nutrindo por elas um notável apego, gostava de brincar e de jogar com elas (ASSIS, 2007, p. 71-72).
} 
conseguem se realizar nem mesmo como bebês. Os genes não são suficientes" (WINNICOTT, 1983, p. 43). Ademais, o autor inglês afirma que a possibilidade de existir um ser que, por sentir-se real e integrado em termos psicossomáticos, pode emprestar um sentido de realidade, criar e usar os objetos da realidade compartilhada somente ocorre dentro e a partir de determinadas condições. Para isso, afirma também, que há de um lado, a tendência inata do ser humano à integração e ao amadurecimento e, de outro, o cuidado do ambiente.

Assim, o psicanalista inglês será incisivo em afirmar o completo desamparo e dependência do lactante em relação à sua mãe ${ }^{3}$ que, segundo ele, será aquela que deve propiciar um ambiente favorável para o seu desenvolvimento e seu processo maturacional. Desde este aspecto, remete-se à questão winnicottiana do holding, isto é, da questão do cuidado e da alteridade nessa perspectiva. De modo que o meio, isto é, o ambiente e suas condições, artificiados pela mãe, são fundamentais para o desenvolvimento e o alvorecer de um ser; assim, como diz Winnicott, o bebê faz um "esforço desesperado para encontrar uma base para ser" (WINNICOTT, 1987, p. 116).

Desde Freud, tem-se uma insistência na realidade do desamparo inicial do ser humano, considerando-o como indefeso e frágil, impelindo-o a construir uma fantasia sobre sua total passividade a partir de sua vida íntima com a mãe. Assim, segundo Winnicott, "o bebê se comunica através do seu desamparo e dependência" (WINNICOTT, 1994, p. 95).

Essa comunicação, por sua vez, tem a configuração de ser pré-verbal em que tudo é silêncio e segurança. Desse modo, o bebê demanda, silenciosamente, um ambiente no qual possa confiar e sustentar todas as adversidades no curso do seu processo em direção à maturidade. A mãe, representante desse ambiente confiável, "deve ajudar a criança a pré-dizer qualquer coisa que venha a acontecer fora do normal na sua vida" (WINNICOTT, 1971, p. 73). Sobre isso, diz Winnicott:

Não é verdade que a mãe comunicou-se com o bebê? Ela disse: 'sou confiável - não pode ser uma máquina, mas porque ser do que você está precisando; além disso, me preocupo, e quero providenciar as coisas que você deseja.' Isto é o que chamo de amor neste estágio do seu desenvolvimento (WINNICOTT, 1994, p. 87).

O bebê faz com que o ambiente humano tome todos os cuidados para não abalar a confiabilidade adquirida no mundo ao seu redor, por meio da relação de dependência absoluta que ele estabelece com a mãe caso ela se constitua como o continente que ele necessita, assim como por todos aqueles de quem ele dependa no curso do processo de maturidade.

Assim sendo, em continuidade com a explanação anterior sobre confiabilidade e comunicação mãe-bebê, chega-se ao papel preponderante da ilusão nas proposições

\footnotetext{
${ }^{3}$ Winnicott usa às expensas o termo mãe; contudo, deixa claro que seu conceito tem natureza genérica, isto é, não defende unicamente como a mãe biológica, mas sim, daquele sujeito que tem a preocupação materna e presta o cuidado materno primário com relação ao bebê.
} 
winnicottianas; para o psicanalista inglês, a adaptação da mãe às necessidades do bebê, quando suficientemente boa, possibilita ao filho a ilusão de que este cria uma realidade externa (o seio materno) correspondente à sua capacidade criativa. Em outras palavras, ocorre uma sobreposição entre o que a mãe supre e o que a criança poderia conceber. Assim, psicologicamente, o filho recebe de um seio que faz parte dele e a mãe dá leite a um bebê que, segundo a perspectiva do lactente, é parte dela mesma (Cf. WINNICOTT, 1971, p. 27).

Assim diz o autor inglês: "A mãe, no começo, através de uma adaptação quase completa, propicia ao bebê a oportunidade para a ilusão de que o seio dela faz parte do bebê, de que está, por assim dizer, sob o controle mágico do bebê" (WINNICOTT, 1971, p. 27). Essa ilusão de onipotência seria, portanto, uma suposição (da criança) de que o seio que the é oferecido e o cuidado que lhe é dispensado foram por ele concebidos e estão sob o seu controle onipotente.

Vê-se que, em Winnicott, ilusão não tange a realização de desejo, como em Freud. Tampouco diz respeito à ordem pulsional ou serve de proteção contra 0 desamparo constitutivo, mas sim, implica na conceituação de um território intermediário entre a realidade pessoal e o mundo externo, que se constitui a partir de um paradoxo cujo valor reside em ser sustentado como tal (Cf. GARCIA, 2007, p. 172).

Esse invólucro materno em que é inserido o bebê, irá atuar como um holding que oportunizará um processo de integração, ou seja, todas as particularidades do cuidado materno que antecedem e procedem depois do nascimento se canalizam para a composição de um ambiente de conservação (por isso o termo holding) e de inserção temporal (da maturação) e espacial (com o ambiente).

Desse modo, a função de holding associa-se à confiabilidade e responsabilidade. A partir de uma realidade relacional mãe-bebê em que os eventos se dão de forma satisfatória, o ego da criança encontra ambiente propício para se desenvolver. Com a integração, o bebê atinge o estágio de desenvolvimento em que ele se torna uma unidade, passando a ser capaz de sentir o self como uma unidade, com uma membrana limitadora a ser dotado de um interior e um exterior.

Isso supõe, portanto, um estágio de não-integração que, por sua vez, consiste justamente na dependência primeiramente absoluta do bebê. É nesse sentido que o autor em questão, distinguirá os conceitos de não-integração, integração e desintegração. Assim, faz-se necessário elucidar que o termo 'não-integração' não se confunde com o termo 'desintegração'. O primeiro diz respeito a um estado em que o bebê não vê a necessidade de estar integrado por conta do suporte egóico da mãe; o segundo, por sua vez, conceitua-se como uma defesa a partir de uma falha do holding no estágio de dependência absoluta. Assim, como o cuidado materno conduz à integração egoica, as falhas no cuidado levam à desintegração. Sobre isso, esclarece Winnicott: 


\begin{abstract}
A capacidade que a mãe tem de ir ao encontro das necessidades em constante processo de mutação e amadurecimento deste bebê permite que sua trajetória de vida seja relativamente contínua; permite-lhe, também, vivenciar situações de não-integração ou relaxadas, a partir da confiança que deposita na realidade do fato de o segurarem bem, juntamente com fases reiteradas de integração [nos momentos de excitação e encontro do objeto] que faz parte da tendência inata ao crescimento. O bebê passa, então, com muita facilidade da integração ao conforto descontraído da não-integração e o acúmulo dessas experiências torna-se um padrão e forma a base para as expectativas do bebê. Ele passa a acreditar na confiabilidade dos processos internos que levam à integração em uma unidade (WINNICOTT, 1994, p. 86).
\end{abstract}

Ademais, essa mãe suficientemente boa proposta por Winnicott se afirma a partir do seu antônimo: extremamente boa. Segundo o psicanalista inglês, a mãe deve ser suficientemente, e não extremamente boa.

Essa suficiência, por sua vez, inclui a existência de possíveis falhas que podem ocorrer no curso do desenvolvimento do bebê; este suporta essas falhas, uma vez que podem se apresentar como sendo relativas, isto é, passíveis de serem corrigidas pela mãe e comunicadas a ele em pequenas doses. Segundo Winnicott (1983), o bebê tem a capacidade de registrar essas pequenas falhas; contudo, registra, sobretudo, as tentativas de correção das falhas por parte de sua mãe. Quando as falhas são corrigidas a tempo, o bebê oferece, então, à mãe, as condições necessárias para repetidas correções de falhas ${ }^{4}$. Nisso consiste a adaptação bem-sucedida às falhas maternas e que criará condições para a emergência e o desenvolvimento dos sentimentos de confiabilidade e segurança. Sobre isso, afirma Winnicott:

A partir destas comunicações silenciosas, podemos passar para as formas pelas quais a mãe concretiza exatamente aquilo que o bebê está pronto para procurar, de tal forma que ela lhe dá ideia das coisas que ele está pronto para procurar. O bebê diz (sem palavras, é claro): "Estou precisando de...", e neste momento a mãe vira o bebê de lado ou se aproxima com as coisas necessárias para alimentá-lo, e o bebê pode, então, completar sua frase: "...uma mudança de posição, um peito, mamilo, leite, etc., etc.". Temos que dizer que o bebê criou o seio, mas não poderia tê-lo feito se a mãe não tivesse chegado com o seio exatamente naquele momento (WINNICOTT, 1994, p. 89-90).

Portanto, a importância e o papel da mãe limitam-se à função, por assim dizer, de facilitadora de um processo de amadurecimento que pertence ao bebê. A mãe é

\footnotetext{
${ }^{4}$ Vale dizer que, para Winnicott, essas falhas podem explicar as patologias psicóticas. É a extrema imaturidade do bebê que torna grave as falhas ambientais que estão na base das patologias psicóticas. De fato, no mais primitivo dos estágios iniciais, o da primeira mamada teórica, o bebê é uma mera continuidade de ser e sua única expectativa é continuar a ser. Ele está não-integrado, não tem nenhum sentido de realidade, nem do si-mesmo, nem do mundo. Ele só pode viver nesse estado em função de sua dependência absoluta da mãe e sem nenhuma consciência, seja de sua própria situação, seja das condições que lhe permitem viver nesse estado. (Cf. DIAS, 2011, p. 20). Ademais, sobre isso, afirma Winnicott: "os distúrbios mais insanos ou psicóticos formam-se na base de falhas da provisão ambiental e podem ser tratados, muitas vezes com êxito, por uma nova provisão ambiental" (WINNICOTT, 1983, p. 205). Assim, existem, para o autor, falhas relativas (que podem ser adaptadas) e as falhas absolutas, que estão na etiologia das psicoses.
} 
mera parteira da natureza humana. Seu cuidado deve ser confiável na medida em que, usando toda a sua afetividade para cuidar do bebê, não põe a sua pessoa, enquanto subjetividade, no centro da cena (Cf. DIAS, 2011, p. 42). Segundo Elsa Dias, "é só através da experiência repetida da confiabilidade ambiental que começam a ser constituídos os fundamentos do sentido de ser, de ser real e de poder habitar num mundo real" (DIAS, 2011, p. 15).

Pode-se afirmar que esse mesmo processo do amadurecimento prossegue, o bebê adquire um interior (realidade subjetiva) e um exterior (realidade objetiva) e a confiabilidade do meio ambiente passa, então, a ser "uma crença ou uma introjeção baseada na experiência de confiabilidade" (WINNICOTT, 1994, p. 87). A característica essencial desse ambiente facilitador e materno seria a confiabilidade que, por sua vez, está intimamente ligada à dependência absoluta do bebê com relação à mãe nos estágios primevos da vida; o bebê só pode adquirir tranquilidade na medida em que confia que o mundo continuará vivo e que assim, desta forma, permanecerá, para atendê-lo quando precisar de acordo com sua demanda, segundo sua majestade e onipotência. Sobre isso, Winnicott afirma que "a mãe, no começo, através de uma adaptação quase completa, propicia ao bebê a oportunidade para a ilusão de que o seio dela faz parte do bebê, que está, por assim dizer, sob o controle mágico do bebê" (WINNICOTT, 1971, p. 26). É nessa área de ilusão e onipotência que cabe à mãe preservar e continuar.

Isso significa que lhe é permitido habitar, durante o tempo necessário, num mundo subjetivo no qual ele exerce um controle mágico, onipotente, ou seja, as experiências acontecem no momento exato da necessidade do bebê e correspondem ao seu gesto espontâneo; o seio aparece quando a fome ou a precisão de encontrar algo aponta e desaparece quando a tensão cessa. Nesse mundo, nenhuma amostra da realidade externa se intromete, porque a mãe evita qualquer irrupção imprevisível, e incompreensível para ele, da realidade (externa para o observador) que o bebê ainda não pode abarcar na sua experiência (DIAS, 2011, p. 22).

Desta forma, os cuidados maternos que mantêm o bebê na sua área de ilusão de onipotência estão direcionados, sobretudo, no sentido de evitar que a criança seja surpreendida com um sentido de realidade para o qual ainda não está preparada. $A$ mãe protege o filho da irrupção de qualquer amostra da realidade externa, incompreensível para ele, e impossível de ser abarcada no âmbito de sua onipotência. Devido à sua extrema imaturidade, o bebê só pode fazer experiências, sentidas como reais, no único sentido de realidade para o qual está preparado: a realidade do que é subjetivo.

A mãe traz uma amostra, um pedaço do mundo até o filho adequada às suas necessidades e proporciona uma experiência de onipotência ao permitir que o infante tenha a ilusão de que o que foi encontrado seja algo por ele criado e esteja sob o seu controle mágico. Portanto, o ambiente favorecedor será aquele que, tornando possível 
a ilusão de onipotência, favorece a espontaneidade do indivíduo, a progressiva instauração do ego e a fusão dos componentes da motilidade e do erotismo.

Nesse processo, a primeira tarefa da mãe é permitir o acesso do bebê à ilusão de que o mundo é uma criação sua, o que significa alimentar a sua onipotência, tal como propusera Winnicott: "toda criança precisa tornar-se capaz de criar o mundo (a técnica adaptativa da mãe faz com que isso seja sentido como um fato) caso contrário, o mundo não terá significado" (WINNICOTT, 1987, p. 44); e a segunda, é favorecer a instauração de um processo gradativo de desilusão. Isso só acontece se, e somente se, a mãe respeitar o tempo de tolerância da criança em relação às suas idas e vindas. Para o autor inglês, toda e qualquer função psíquica só se desenvolve na presença do outro.

Para Winnicott, desde o nascimento, o ser humano se insere no problema daquilo que é "objetivamente percebido e aquilo que é subjetivamente concebido e, na solução desse problema, não existe saúde para o ser humano que não tenha sido iniciado suficientemente bem pela mãe" (WINNICOTT, 1971, p. 26). E aprofunda:

\footnotetext{
De início, o relacionamento é com um objeto subjetivo, e é uma longa jornada daqui até o desenvolvimento e estabelecimento da capacidade de se relacionar com um objeto que é percebido objetivamente e que tem a possibilidade de ter uma existência separada, uma existência exterior ao controle onipotente do indivíduo (WINNICOTT, 1983, p. 81).
}

A partir desse trajeto, pode-se afirmar, juntamente com Winnicott, que a passagem da indiferenciação para a diferenciação se dá a partir da necessária ausência da mãe que deve ser, por sua vez, gradativa; só assim a dependência relativa, que outrora foi absoluta, tomará o rumo para a independência.

Relacionado ao conceito de ilusão, está a emergência dos fenômenos transicionais: é o espaço, por excelência, da constituição do bebê enquanto sujeito, o qual permitirá a transição de um sentido de realidade subjetiva para outro, objetivamente percebida. Assim, se o bebê adquire sentimentos de confiança e fidedignidade que foram sendo depositados nele pela mãe durante a experiência de ilusão, muitos processos mentais passam a se desenvolver no desenvolvimento seguinte, isto é, da dependência à independência.

Aqui, a ilusão se apresenta, portanto, como a superposição do seu criado (e oferecido) e, aos poucos, este espaço dá lugar a uma área transicional que 'suaviza' o impacto interno/externo e serve à função de repouso criativo. O fenômeno transicional ocorre no período de dependência relativa e representa o início da antiga unidade mãe-bebê, consequência do processo de desilusão gradativa. A realidade externa começa, então, a se introduzir, colocando em questão o controle onipotente do lactante. Assim, é só a partir de uma suficiente experiência inicial na área da ilusão que se dá o surgimento dessa zona intermediária, agora ocupada pelos objetos e fenômenos transicionais que dão corpo à ilusão (GARCIA, 2007, p. 173). 
Ademais, o psicanalista inglês enriquece e modifica profundamente a concepção freudiana sobre o ego a partir do momento que essa área intermediária afirmada por ele será fundamental para a organização do ego, assinalando a existência de uma dimensão da experiência humana diferente daquela caracterizada, na psicanálise ortodoxa, pela vida pulsional e sua necessidade de satisfação. Assim, a crítica winnicottiana se dirige no sentido de que, segundo ele, Freud se limitou a considerar as realidades interna e externa, ignorando o espaço intermediário como lócus onde se opera a experiência autocriativa do sujeito (Cf. PLASTINO apud BEZERRA JUNIOR; ORTEGA, 2007, p. 209).

À medida que o amadurecimento prossegue, e se a confiabilidade é mantida, a ilusão de onipotência do início perde gradualmente o teor de onipotente e se transforma na capacidade de crença (no sentido de acreditar e confiar). Tal capacidade, por sua vez, tenderá a ser completada com o tempo e preenchida por objetivos, metas, crenças, etc. Sobre isso, diz Winnicott: "o bebê adquire um interior e um exterior, a confiabilidade do meio ambiente passa então a ser uma crença, uma introjeção baseada na experiência da confiabilidade (humana e não mecanicamente perfeita)" (WINNICOTT, 1994, p. 86).

Então, o elemento que seria utilizado para auxiliar em tal passagem de transição seria aquilo que Winnicott chamou de objeto transicional que pode ser o dedo, um ursinho, uma canção, um 'obrigado' que aprendeu a dizer ou outros elementos que seriam carregados de afeto representando para a criança a sua mãe. Em síntese, para Winnicott, deve-se, portanto, criar um "espaço potencial que pode se transformar em objeto transicional, o símbolo da confiança e da união entre o bebê e a mãe, uma união que não envolve a interpretação" (WINNICOTT, 1994, p. 89). Tais conceitos foram assim elaborados para dar conta dos processos do viver e do adoecer do ser humano, complexidade verificada na experiência clínica do autor inglês. Sobre isso, Winnicott afirma:

\begin{abstract}
O objeto transicional e os fenômenos transicionais iniciam todos os seres humanos com o que sempre será importante para eles, isto é, uma área neutra de experiência que não será contestada. Do objeto transicional, pode-se dizer que se trata de uma questão de concordância, entre nós e o bebe, de que nunca formulemos a pergunta: 'Você conceber isso ou lhe foi apresentado a partir do exterior?' O importante é que não se espere decisão alguma sobre esse ponto. A pergunta não é para ser formulada (WINNICOTT, 1971, p. 28).
\end{abstract}

A tarefa, protagonizada pela mãe, de ser propiciadora tanto da experiência ilusória quanto da desilusão gradativa. Winnicott insiste no papel do desmame nesse processo de desenvolvimento. Para ele, a realidade da ilusão-desilusão é subjacente ao término da amamentação justamente para que tal cessamento possa ser encarado, pelo lactante, como algo normal; do contrário, se o processo desilusório se extravia, não acontece o se tudo corre bem tão caro para a psicanálise inglesa. A singularidade 
e a pluralidade das experiências pessoais e as instabilidades da vida de cada um, constituem a marca de origem deste potencial em que a produção criativa de certa forma evita a separação, contraditoriamente, separando-a!

\section{CONCLUSÃO}

Vê-se que, no devido tempo, o bebê terá de aceitar o fato da existência externa do mundo, sobre a qual não tem controle, e tal processo de desilusão é fundamental. Mas a desilusão, com as aquisições que lhe são próprias, só pode acontecer e favorecer o crescimento sobre uma bem fundada capacidade para a ilusão. Para Winnicott, é enganoso pensar que a aquisição do sentido de realidade, pelo bebê, depende da insistência da mãe quanto à natureza externa e objetiva das coisas do mundo externo. Somente após uma bem instalada capacidade ilusória é possível esperar que, aos poucos, a criança seja capaz de aceitar a existência independente do mundo externo e assimilar as devidas desilusões.

A relação do bebê com a sua mãe é tida por ele como a satisfação, por excelência de suas necessidades, fato que o faz ter a ilusão de controlá-la. É essa mãe que, gradualmente, vai colocar essa criança em contato com a realidade, própria da vida, na qual a capacidade de esperar e de suportar possíveis frustrações se faz necessária como componente de uma saudável estrutura de personalidade. Essa capacidade, por sua vez, só será viabilizada a partir do momento em que houver a vigência da confiança básica do bebê e da criança em sua mãe. Nesse sentido, Winnicott é enfático em abordar a questão da confiabilidade sob a realidade do desamparo e do papel materno. A mãe deve ser suficiente, satisfatória, regular, baseando-se na virtude da justa-medida. A manutenção da majestade da criança ou atender à demanda do controle fetichista da mesma tornará a situação intransigente às falhas e ausências que ocorrem no processo de maturação.

Hoje muito se fala sobre a égide de uma pulsão sem a menor gravidade, uma sociedade que vive sob o império da liberdade sem aporias. Tal conjuntura incide na realidade pedagógica familiar onde se constata que as antigas tradições e costumes que regiam a relação mãe e filho (a) estão passando, em alguns casos, por uma profunda mutação. Dentre os fatos que vale mencionar, são: filhos que emitem ordem aos pais e são obedecidos, filhos que raramente ouvem uma resposta negativa dos seus pais (e ouvirão, futuramente, de um professor, chefe de trabalho, terapeuta, etc), filhos que desconhecem limites, pais que acompanham os filhos no uso de aditivos, dentre outros.

A providência parece funcionar unicamente no sentido do prazer e nunca na realidade que, por sua vez, adiaria a satisfação e faria com que o sujeito tenha que lidar com a frustração e o desamparo. Todas essas novidades familiares recaem sobre a questão do amadurecimento e a confiabilidade nas relações familiares: o controle 
hipotético que o infante possuiria parece tornar-se efetivo, ou seja, ele detém o manejo fetichista do objeto que está sujeito ao seu controle. Não existe ilusão, efetivamente se detém o controle do mundo.

Por fim, sofisticando a psicanálise freudiana, o psicanalista inglês irá reforçar a ideia de que o inconsciente sempre se constitui através de outrem, é transindividual. E a conservação da vida e o advento do ser só se dá mediante a inserção de um segundo indivíduo. É relacional no nascimento, na sobrevivência, na segurança e na maturação. E o crivo para uma relação autêntica que esteja a serviço da saúde e da integração é a confiabilidade.

\section{REFERÊNCIAS}

ANDRÉ, Jacques. Vocabulário básico de psicanálise. São Paulo: Martins Fontes, 2015.

ASSIS, Árbila Luiza Armindo. Influências da psicanálise na educação: uma prática psicopedagógica. Curitiba: Ibpex, 2007.

BEZERRA JUNIOR, Benilton; ORTEGA, Francisco. Winnicott e seus interlocutores. Rio de Janeiro: Relume Dumará, 2007.

DIAS, Elsa Oliveira. Sobre a confiabilidade e outros estudos. São Paulo: DWW Editorial, 2011.

FREUD, Sigmund. Uma dificuldade no caminho da psicanálise (1917). In FREUD, Sigmund. História de uma neurose infantil e outros trabalhos: (1917-1918). Rio de Janeiro: Imago, 1996a. 17v.

FREUD, Sigmund. Cinco lições de psicanálise (1910). In FREUD, Sigmund. História de uma neurose infantil e outros trabalhos: (1917-1918). Rio de Janeiro: Imago, 1996b. $17 \mathrm{v}$.

FREUD, Sigmund. Além do princípio de prazer (1920). In: FREUD, Sigmund. Além do princípio de prazer, psicologia de grupo e outros trabalhos: (1920-1922). Rio de Janeiro: Imago, 1996c. 18v.

FREUD, Sigmund. Os instintos e suas vicissitudes (1915). In: FREUD, Sigmund. A história do movimento psicanalítico, artigos sobre a metapsicologia e outros trabalhos: (1914-1916). Rio de Janeiro: Imago, 1996d. 14v. 393 p.

FREUD, Sigmund. O Mal-Estar na Civilização (1930). In: FREUD, Sigmund. O futuro de uma ilusão, o mal-estar na civilização e outros trabalhos: (1927-1931). Rio de Janeiro: Imago, 1996e. $21 \mathrm{v}$.

GARCIA, Claudia Amorim. O conceito de ilusão em psicanálise: estado ideal ou espaço potencial? Estudos de Psicologia, Rio de janeiro, v. 12, n. 2, p. 169-175, ago. 2007. 
LAPLANCHE, Jean; PONTAILS, Jean-Bertrand. Vocabulário de Psicanálise. São Paulo: Martins Fontes, 2001.

MATOS, Olgária. A escola de Frankfurt: luzes e sombras do lluminismo. São Paulo: Moderna, 2006.

WINNICOTT, D. W. O brincar e a realidade. Rio de Janeiro: Imago, 1971.

WINNICOTT, D. W. Os Bebês e suas Mães. São Paulo: Martins Fontes, 1994.

WINNICOTT, D. W. O ambiente e os processos de maturação. Porto Alegre: Artes Médicas, 1983.

WINNICOTT, D. W. Privação e delinquência. São Paulo: Martins Fontes, 1987.

WINNICOTT, D. W. Textos selecionados: da pediatria à psicanálise. Rio de Janeiro: Francisco Alves, 1978. 